\title{
Imo1273, a novel gene involved in Listeria monocytogenes virulence
}

\author{
Armelle Bigot, ${ }^{1,2}$ Catherine Raynaud, ${ }^{1,2}$ Iharilalao Dubail, ${ }^{1,2}$ \\ Marion Dupuis, ${ }^{1,2}$ Hamid Hossain, ${ }^{3}$ Torsten Hain, ${ }^{3}$ Trinad Chakraborty ${ }^{3}$ \\ and Alain Charbit ${ }^{1,2} \dagger$ \\ 1 Université Paris Descartes, Faculté de Médecine René Descartes, Paris F-75015, France \\ ${ }^{2}$ Inserm, U570, Unité de Pathogénie des Infections Systémiques, Paris F-75015, France \\ ${ }^{3}$ Institute for Medical Microbiology, Justus-Liebig-University, Frankfurter Strasse 107, D-35392 \\ Giessen, Germany
}

Correspondence

Alain Charbit

alain.charbit@inserm.fr

Received 15 July 2008

Revised 24 October 2008

Accepted 8 November 2008
Listeria monocytogenes is a foodborne pathogen able to infect humans and many other mammalian species, leading to serious, often fatal disease. We have previously identified a fivegene locus in the genome of $L$. monocytogenes EGD-e which comprised three contiguous genes encoding paralogous type I signal peptidases. In the present study, we focused on the two distal genes of the locus (Imo1272 and Imo1273), encoding proteins sharing significant similarities with the YlqF and RnhB proteins, respectively, of Bacillus subtilis. Imo1273 could complement an Escherichia coli $r n h A-r n h B$ thermosensitive growth phenotype, suggesting that it encodes a functional RNase H. Strikingly, inactivation of Imo1273 provoked a strong attenuation of virulence in the mouse model, and kinetic studies in infected mice revealed that multiplication of the Imo1273 mutant in target organs was significantly impaired. However, the mutation did not impair L. monocytogenes intracellular multiplication or cell-to-cell spread in cell culture models.

Transcriptional profiles obtained with an Imo1273-overexpressing strain were compared to those of the wild-type strain, using microarray analyses. The data obtained suggest a pleiotropic regulatory role of Lmo1273 and possible links with amino acid uptake.

\section{INTRODUCTION}

The Gram-positive bacterium Listeria monocytogenes is a foodborne pathogen that is widespread in the environment. This facultative intracellular pathogen is responsible for sporadic severe infections in humans and numerous animal species (Farber \& Peterkin, 1991; Vazquez-Boland et al., 2001). L. monocytogenes is capable of invading most host cells, and the molecular mechanisms of its intracellular parasitism have been investigated extensively (Hamon et al., 2006). We have previously identified a five-gene locus, designated sip (lmo1269lmo1273), in the genome of L. monocytogenes EGD-e, encoding three paralogous type I signal peptidases (SPases

†Present address: Faculté de Médecine Necker, 156 rue de Vaugirard, 75730 Paris Cedex 15, France.

Abbreviations: BMM, bone-marrow-derived macrophages; i.v., intravenous(ly); SPase I, type I signal peptidase.

The microarray data associated with this paper have been deposited in the ArrayExpress database (http://www.ebi.ac.uk/arrayexpress) under the accession number E-MEXP-1162.

A supplementary table of primers and three supplementary figures are available with the online version of this paper.
I) (Bonnemain et al., 2004) involved in bacterial virulence. We showed that this locus was under the control of two distinct promoters, one preceding lmo1269 (designated sipX) and a second preceding $l m o 1271$ (designated sipZ) (Raynaud \& Charbit, 2005). The two distal genes of the locus (Imo1272 and Imo1273), which are co-transcribed with the SPase I genes (Raynaud \& Charbit, 2005), encode proteins sharing significant similarities with the $\mathrm{YlqF}$ and RnhB proteins, respectively, of Bacillus subtilis. In the latter organism, RnhB is involved in RNA-DNA heteroduplex degradation (Itaya et al., 1999; Ohtani et al., 1999a) and YlqF participates in ribosome biogenesis (Matsuo et al., 2006; Uicker et al., 2007).

Currently, at least 15 RNases are known in Escherichia coli and at least 10 in B. subtilis (Condon, 2003). Among these RNases, RNase H (Crouch, 1990; Katayanagi et al., 1990) has been defined as an enzyme that specifically degrades the ribonucleotide moiety in RNA-DNA hybrid molecules (Ohtani et al., 1999a, b). RNases $\mathrm{H}$ are classified into two major families, type I and type II, which are evolutionarily unrelated. Bacterial RNases HI (encoded by $r n h A$ ), eukaryotic RNases $\mathrm{H} 1$ and retroviral RNases $\mathrm{H}$ are members of the type I RNase H family. Bacterial RNases 
HII and RNases HIII (encoded by $r n h B$ and $r n h C$, respectively), archaeal RNases HII and eukaryotic RNases $\mathrm{H} 2$ are members of the type II RNase $\mathrm{H}$ family (Zhang et al., 1997). The role of RNase $\mathrm{H}$ in bacterial cell growth has recently been reassessed in B. subtilis (Fukushima et al., 2007). This study revealed that $B$. subtilis possesses four RNase $\mathrm{H}$ encoding genes $(r n h B, r n h C, y p d Q$ and $y p e P)$. Although RNase $\mathrm{H}$ had been previously reported to be essential in B. subtilis, the four genes could be simultaneously deleted, demonstrating that RNase $\mathrm{H}$ activity is dispensable for the bacterium. However, the growth rates of mutants with two or more $r n h$ genes inactivated were low, indicating that this activity is required for normal cell growth and may thus participate in DNA replication.

The genome of L. monocytogenes EGD-e encodes one putative RNase HI (Imo1880), one putative RNase HII (Imo1273) and one putative RNase HIII (lmo1228). The aim of the present work was to address the role of $l$ mo1273 in virulence. The data presented show that lmo1273 controls the expression of multiple genes and is involved in the in vivo survival of $L$. monocytogenes.

\section{METHODS}

Bacterial strains, plasmids and growth conditions. We used the reference strain of $L$. monocytogenes EGD-e, which belongs to serovar 1/2a (Glaser et al., 2001). E. coli strain DH5 $\alpha$ was used for all plasmid constructions prior to their introduction into L. monocytogenes. E. coli was grown in LB; L. monocytogenes was grown in BHI rich medium. Plasmids pUC19 (Vieira \& Messing, 1985) or LITMUS28 (New England Biolabs) were used to clone all PCR-amplified sequences from EGD-e and to construct the required deletions. Deletions were then transferred to the shuttle vector pAUL-A (thermosensitive in Listeria: Lingnau et al., 1995) for subsequent recombination into the chromosome. Strains harbouring plasmids were grown in the presence of the following antibiotics: for pUC19, pTrc99A and LITMUS28 derivatives, ticarcillin $100 \mu \mathrm{g} \mathrm{ml}^{-1}$; for pAUL-A derivatives, erythromycin $150 \mu \mathrm{g} \mathrm{ml} l^{-1}(\text { E. coli) and } 5 \mu \mathrm{g} \mathrm{ml})^{-1}$ (L. monocytogenes) and kanamycin $50 \mu \mathrm{g} \mathrm{ml}^{-1}$; for pPL2 derivatives, chloramphenicol, $5 \mu \mathrm{g} \mathrm{ml}{ }^{-1}$. PCR amplifications were performed using Taq polymerase (Finnzymes), according to the manufacturer's recommendations. Restriction enzymes and ligase were purchased from New England BioLabs. Primers were purchased from Eurogentec.

Construction of $\Delta / m 01273$ chromosomal deletion mutant. We replaced the coding sequence (nucleotides 5-780) of the lmo1273 gene by the promoterless aphA3 cassette conferring kanamycin resistance. A 760 bp EcoRI/BamHI-digested double-stranded DNA fragment (A) upstream of lmo1273 and a 790 bp BamHI-SalI DNA fragment (B) downstream of $l m o 1273$ were amplified by PCR using L. monocytogenes EGD-e genomic DNA with primers 1-2 and 3-4 respectively (see Supplementary Table S1, available with the online version of this paper, for primer sequences). After digestion, fragments A and B were successively cloned into pUC19 vector between the EcoRI and the Sall site. The pUC19-AB plasmid was digested with BamHI, and the 800 bp aphA3 cassette flanked by two BamHI restriction sites was inserted into pUC19-AB. The $2.4 \mathrm{~kb}$ EcoRI-SalI A-aphA3-B fragment was then cloned into the thermosensitive shuttle vector pAUL-A. Plasmid pAUL-A-aphA3-B was then electroporated into L. monocytogenes EGD-e (Park \& Stewart, 1990) and the transformants were selected for $\mathrm{Em}^{\mathrm{R}}$ at $30{ }^{\circ} \mathrm{C}$.
The L. monocytogenes $\Delta l$ mo1273 chromosomal mutant was obtained by allelic replacement, using the classical two-step procedure described previously (Lingnau et al., 1995). First, chromosomal integration of the recombinant plasmid was achieved by growing the bacteria at the non-permissive temperature of $37^{\circ} \mathrm{C}$. Then, the excision event eliminating the plasmid carrying the wild-type lmo1273 copy was obtained after repeated passages at replication-permissive temperature $\left(30{ }^{\circ} \mathrm{C}\right)$. This procedure led to a $\Delta \operatorname{lmo} 1273$ chromosomal mutant of EGD-e expressing kanamycin resistance. The resulting EGD- $\Delta$ lmo1273 mutant was verified by sequencing analysis of chromosomal DNA using pairs of internal or flanking primers.

Construction of a $\Delta / \mathbf{m o 1 2 7 2}$ chromosomal deletion mutant. We attempted to construct a $\Delta l m o 1272$ mutant by the same procedure in wild-type EGD-e. Two DNA fragments flanking the 1 mo1272 gene (see primers in Supplementary Table S1) were ligated and cloned into the thermosensitive plasmid pAUL-A, yielding pAUL-A-lmo1272. This plasmid was then introduced into EGD-e. Chromosomal integration of the recombinant plasmid was obtained (using the procedure described above for construction of the lmo1273 mutant). The second crossover event, leading to excision of the plasmid, was screened by growing the recombinant bacteria at a permissive temperature for up to 100 generations in the absence of erythromycin. All the clones recovered were either still $\mathrm{Em}^{\mathrm{R}}$ (i.e. had not lost the integrated plasmid) or were $\mathrm{Em}^{\mathrm{S}}$ but had lost the plasmid carrying the mutated Imo1272 region, reconstituting a wild-type chromosomal region. Thus, the second crossover event occurred only when the wild-type Imo1272 allele was kept on the bacterial chromosome, strongly suggesting that the deletion of this gene was not tolerated.

Generation of an internal Imo1273 deletion (Imo1273-ID strain). We also attempted to construct a $\Delta l m o 1272$-lmo1273 double mutant. For this, a $600 \mathrm{bp}$ EcoRI-SmaI double-stranded DNA fragment comprising an internal portion of $\operatorname{lmo1272}$ (A) and a 900 bp SmaI-SalI double-stranded DNA fragment comprising the distal portion of $1 m o 1273$ and downstream region (B) were amplified by PCR from L. monocytogenes (EGD-e) genomic DNA, using primers listed in Supplementary Table S1. After digestion, fragments A (EcoRI-SmaI) and B (SmaI-SalI) were ligated and cloned into the EcoRI-SalI sites of pUC19. The vector was digested with SmaI and the 900 bp aph $3^{\prime}$ cassette (conferring Km resistance) flanked by two SmaI restriction sites was inserted into pUC19-AB. To permit allele exchange in L. monocytogenes the EcoRI-SalI fragments containing the $\mathrm{Km}$ cassette were subcloned into the corresponding restriction sites of the thermosensitive shuttle vector pAUL-A, to give plasmid pAUL-A : A-aph3'-B. The L. monocytogenes chromosomal mutant was constructed by allelic replacement of the A-aph $3^{\prime}$-B fragment by the classical two-step procedure routinely used in our laboratory. The construction was checked by PCR sequence analysis. Unexpectedly, the resulting construct possessed an intact $l m o 1272$ gene and carried only an internal deletion of 224 bases within $1 m 01273$ (fusing out of frame the first $433 \mathrm{bp}$ and the last $125 \mathrm{bp}$ of the gene).

Construction of the $\Delta / \mathbf{m o 0 8 4 7}$ chromosomal deletion mutant. We generated a deletion of the Imo0847 sequence by allelic replacement using the pMAD thermosensitive shuttle vector (Arnaud et al., 2004). Briefly, upstream and downstream sequences of the gene were amplified by PCR using primers 51-52 and 53-54 (see Supplementary Table S1) and cloned in pMAD between the EcoRI and the BamHI unique site. The resulting plasmid pMAD$\Delta l m o 0847$ was electroporated in EGD-e. Integration of the plasmid into the chromosome was obtained after $48 \mathrm{~h}$ of culture at restrictive temperature $\left(42^{\circ} \mathrm{C}\right)$. Then, the excision event eliminating the plasmid carrying the wild-type 1 mo0847 copy was obtained after repeated passages at replication-permissive temperature $\left(30{ }^{\circ} \mathrm{C}\right)$. The resulting EGD- $\Delta l m o 0847$ mutant was verified by sequence analysis of chromosomal DNA using pairs of flanking primers. 
Electron microscopy. Bacteria grown to the exponential phase $\left(\mathrm{OD}_{600} 0.6\right)$ were processed for observation by electron microscopy. Fixation of the bacteria and embedding in Epon resin was done as described by Frehel \& Leduc (1987). Thin sections were stained with uranyl acetate and lead citrate before observation with a JEOL 100 CX II transmission electron microscope.

\section{Complementation studies}

Functional complementation in $E$. coli. The coding sequence of the Imo1273 gene of L. monocytogenes EGD-e was amplified by PCR with primers 17 and 18. The PCR product was digested by NcoI and Bam HI and cloned into the pTrc99A vector (Pharmacia Biotech; GenBank accession number M22744), which allows IPTG-inducible expression of the insert via the hybrid trp/lac promoter. pTrc99AImo1273 was then electroporated into the temperature-sensitive E. coli strain MIC2067 (kindly provided by M. Itaya). The temperaturesensitive growth of this strain resulted from the $r n h A$ and $r n h B$ mutations (Itaya et al., 1999). We tested, at various IPTG levels, the ability of strains MIC2067 and MIC2067/pTrc99A-lmo1273 to form colonies on plates incubated at $37{ }^{\circ} \mathrm{C}$ or $42{ }^{\circ} \mathrm{C}$, compared to the number of colony-forming units (c.f.u.) obtained at $30^{\circ} \mathrm{C}$.

Complementation of the Imo1273 deletion using the integrational vector pPL2. The lmo1273 coding sequence (including the ribosomebinding site) was amplified from EGD-e genomic DNA by PCR using primers 22 and 24 . To ensure efficient transcription, Imo1273 was cloned downstream of the $\mathrm{P}_{\text {sip } X}$ promoter (Raynaud \& Charbit, 2005), the main promoter of the sip locus. The $\mathrm{P}_{\text {sip } X}$ region was amplified with primers 20 and 21. Digested $\mathrm{P}_{\text {sipX }}$ and 1 mo1273 PCR products were subcloned together in the LITMUS28 cloning vector. Digestion of the resulting plasmid with $S a c \mathrm{I}$ and $K p n \mathrm{I}$ produced a $1 \mathrm{~kb}$ insert, which was ligated into the SacI/KpnI-restricted vector pPL2 (Lauer $e t$ al., 2002). The resulting pPL2- $\mathrm{P}_{\text {sipX }}$ lmo1273 vector was electroporated into L. monocytogenes $\Delta l m o 1273$ and a transformant was selected on BHI chloramphenicol plates. Integration of the resulting vector in the tRNA $^{\text {Arg }}$ region was confirmed by PCR as described by Lauer et al. (2002).

\section{Expression of Imo1273 under $\mathbf{P}_{\text {sipX }}$ promoter control in pAT28} (pP $\mathbf{X}$ Imo1273) in EGD-e. A strain overexpressing lmo1273 was constructed by placing the lmo1273 gene under the control of the $\mathrm{P}_{\text {sipX }}$ promoter in the multicopy plasmid pAT28. Briefly, $\mathrm{P}_{\text {sipX }}$ was amplified using primers 19 and 21, and $l m o 1273$ was amplified using primers 22 and 23 . The two DNA fragments obtained were cloned together in pUC19. The EcoRI/SphI-digested product was then cloned into pAT28 and the resulting vector introduced in EGD-e by electroporation. The final construction was checked by sequencing and $l$ mo1273 expression measured by quantitative RT-PCR.

\section{Transcriptomic analyses: RNA isolation, labelling with Cy dyes,} hybridization and microarray analysis. Bacteria were grown in $\mathrm{BHI}$ to $\mathrm{OD}_{600} 1.0$ (late exponential phase) and RNA was stabilized using the RNAprotect bacteria reagent (Qiagen) according to the manufacturer's recommendations. For each strain, RNA was extracted from three independent biological samples. Briefly, bacterial total RNA was isolated, reverse transcribed and hybridized to a whole-genome microarray, and microarray data were analysed as described previously (Chatterjee et al., 2006). Hybridizations were performed with cDNAs from (i) EGD-e versus $\Delta l m o 1273$ and (ii) EGD-e versus the overexpressing strain (EGD-e/pP $\mathrm{P}_{\mathrm{X}} l$ mo1273). After hybridizations, microarray slides were imaged with a Generation III array scanner (GE Healthcare) and the fluorescent signal intensities from each spot on the microarray slide were quantified using ImaGene 7.5 software (BioDiscovery). The cut-off for significantly differentially expressed genes was set with a $q$-value of $\leqslant 5 \%$ and a fold change $\geqslant 2$. The microarray data associated with this paper have been deposited in the ArrayExpress database (http://www.ebi.ac.uk/ arrayexpress) under the accession number E-MEXP-1162.

Quantitative PCR analysis. Real-time RT-PCR was conducted on total RNA samples isolated independently from the transcriptome analysis experiment (three independent biological samples). Total RNA was extracted as described above, with the only modification that RNAprotected bacteria were lysed by mechanical disruption in a Fastprep apparatus instead of by chemical disruption using lysozyme, mutanolysin and proteinase K. Forward and reverse primer were purchased from Eurogentec and are described in Supplementary Table S1. cDNA was obtained using the Superscript II kit from Invitrogen according to the manufacturer's recommendation, with $250 \mathrm{ng}$ total RNA. Quantitative real-time PCR was performed on an Applied Biosystems 7700 sequence detection thermocycler for 40 cycles with $5 \mu \mathrm{l}$ of $1 / 10$ cDNA dilution, $10 \mu \mathrm{l}$ of Power SYBR green PCR master mix $2 \times$ (Applied Biosystems) and $5 \mathrm{pmol}$ of each primer. For each pair of primers, a water control and a control without reverse transcriptase for each RNA sample (to ensure absence of genomic DNA contamination) were included. The quantity of cDNA for each gene was normalized to the quantity of gyrA cDNA. PCR products were run on a $2 \%$ agarose electrophoresis gel to check specificity of the amplification.

\section{Intracellular multiplication}

Cell cultures. Mouse macrophage cell line J774 (ATCC TIB67) and human colon carcinoma cell line Caco-2 (ATCC HTB37) were propagated as previously described (Dramsi et al., 1995) in DMEM containing $10 \%$ fetal bovine serum. Cells were seeded at a concentration of $2 \times 10^{5}$ cells per well in 12-well tissue culture plates (Falcon). Monolayers were used $24 \mathrm{~h}$ after seeding. Bone-marrowderived macrophages (BMM) from a BALB/c mouse were obtained and cultured as described previously (de Chastellier \& Berche, 1994).

Kinetics of infection. The invasion assays were carried out essentially as described previously (Bigot et al., 2006). Briefly, cell monolayers were incubated for $30 \mathrm{~min}$ (BMM and J774) or $1 \mathrm{~h}(\mathrm{Caco}-2)$ at $37{ }^{\circ} \mathrm{C}$ with the bacterial suspensions in Dulbecco's modified Eagle medium (multiplicities of infection 0.1 for BMM, 1 for J774, and 100 for Caco2) to allow the bacteria to enter. After washing (time zero of the kinetic analysis), the cells were incubated for several hours in fresh culture medium containing gentamicin $\left(50 \mu \mathrm{g} \mathrm{ml}^{-1}\right)$ to kill extracellular bacteria. At several time points, cells were washed three times in RPMI and processed for counting of infecting bacteria. Cells were lysed with distilled water. The titre of viable bacteria released from infected cells was determined by spreading dilutions of the lysate onto plates of BHI medium. The assay was performed in triplicate for each strain and time point in an experiment. Each experiment was repeated at least twice.

Plaque formation assays. These assays were performed essentially as described by Chatterjee et al. (2006). L929 murine fibroblast cells were grown to monolayers in 6-well tissue culture plates in RPMI 1640 supplemented with $5 \%$ fetal calf serum (FCS). The cells were infected with $8 \mu \mathrm{l}$ of a $10^{-4}$ dilution of a washed bacterial culture with an $\mathrm{OD}_{600}$ of 1.0 for $2 \mathrm{~h}$ at $37{ }^{\circ} \mathrm{C}$ in a humidified incubator and subsequently incubated for $30 \mathrm{~min}$ in the presence of $50 \mu \mathrm{g}$ gentamicin $\mathrm{ml}^{-1}$. The agarose overlay contained $1 \%$ agarose in minimal essential medium, $5 \%$ FCS, glutamax (PAA Laboratories), nonessential amino acids (Gibco), and $10 \mu \mathrm{g}$ gentamicin $\mathrm{ml}^{-1}$. Experiments were carried out in duplicate. After 3 days incubation at $37^{\circ} \mathrm{C}$, wells were stained with neutral red and examined for plaque formation.

\section{Determination of virulence in the mouse model.}

Infection of mice. Specific-pathogen-free 6- to 8-week-old female Swiss mice (Janvier) were used. Bacteria were grown for $18 \mathrm{~h}$ in BHI 
broth, centrifuged, appropriately diluted in $0.15 \mathrm{M} \mathrm{NaCl}$, and inoculated $(0.5 \mathrm{ml})$ intravenously (i.v.) into mice via the lateral tail veins. Groups of five mice were challenged i.v. with various doses of bacteria, and mortality was monitored for 10 days. The virulence of the mutant was estimated by using the $50 \%$ lethal dose $\left(\mathrm{LD}_{50}\right)$ with the Probit method (Finney, 1971). For strains carrying pAT28 or a derivative plasmid, mice were pre-treated with spectinomycin $(1 \mathrm{mg}$ per mouse per day) in order to overcome in vivo instability of the recombinant plasmid.

Kinetics studies. Mice were inoculated i.v. in the lateral tail veins. At days $1,3,4,5$ and 6 , groups of five mice were sacrificed, and their spleens, livers and brains were aseptically removed and separately homogenized in $0.15 \mathrm{M} \mathrm{NaCl}$. Bacterial numbers in organ homogenates were determined at various intervals on BHI plates. Five hundred microlitres of bacterial suspension containing $10^{6.1}$ bacteria were injected per mouse. Animal experiments were performed according to the INSERM guidelines for husbandry of laboratory animals.

\section{RESULTS}

\section{Imo1273 encodes an RNase H homologue}

The sip locus of L. monocytogenes comprises five genes (lmo1269-lmo1273). The three first genes of the locus (lmo1269-lmo1271) encode paralogous copies of SPases I, and were hence designated $\operatorname{sip} X, \operatorname{sip} Y$ and sipZ. The role of SPases I is to remove the signal peptides of preproteins exported by the general secretory pathway. Whereas SipX and SipZ perform distinct functions in pathogenicity, SipZ is the major SPase I of L. monocytogenes (Bonnemain et al., 2004).

The fourth gene of the locus, 1 mo1272, encodes a protein of 287 amino acids homologous to B. subtilis YlqF (58\% amino acid identity). It has been experimentally demonstrated that B. subtilis $y l q F$ encodes a GTP-binding protein that participates in the late step of $50 \mathrm{~S}$ ribosomal subunit assembly (Matsuo et al., 2006). Moreover, $y l q F$ has been shown to be an essential gene in B. subtilis (Uicker et al., 2007). GTPases control a wide variety of biological processes, including protein synthesis and cell cycle control. Most bacteria generally encode several highly conserved GTP-binding proteins of unknown function (at least 11 in B. subtilis), many of which are essential for growth (Morimoto et al., 2002). The last gene of the locus, Imo1273, encodes a putative RNase HII of 261 amino acids, sharing $51 \%$ amino acid identity with the $r n h B$-encoded RNase HII of B. subtilis.

We have shown previously that the expression of the sip locus is regulated by two different promoters, $\mathrm{P}_{\operatorname{sip} X}$ and $\mathrm{P}_{\text {sipZ }}$, producing a large transcript covering the entire locus (sipX-lmo1273) and a shorter one compatible with a transcription starting upstream of sipZ (sipZ-lmo1273) (Bonnemain et al., 2004; Raynaud \& Charbit, 2005). Notably, the genomic organization and DNA sequence of the locus are highly conserved in the other sequenced Listeria genomes, including in L. innocua and in the recently sequenced genome of $L$. welshimeri (Hain et al., 2006). A computer-assisted analysis of all the complete bacterial genomes available at the Center for Genomic Research (TIGR, http://www.tigr.org/tigr-scripts/CMR2/ CMRGenomes.spl), searching for the presence of a putative $r n h B$ gene in the immediate vicinity of a sip and/or $y l q F$ gene, revealed that several genomes (including those of strains of Bacillus anthracis, Clostridium tetani and Lactobacillus sakei) had a genetic organization similar to that of L. monocytogenes (Supplementary Fig. S1). In a number of other genomes, and in particular in all the mycobacterial genomes available, the genes sip and $r n h B$ are contiguous and in the same orientation. Finally, as in $B$. subtilis and in Streptococcus species, the gene $r n h B$ can be preceded by a $y l q F$ orthologue, but these genes are not located next to any sip gene.

\section{Functional complementation in E. coli}

Several thermosensitive mutants of $E$. coli that form colonies at $30{ }^{\circ} \mathrm{C}$ but not at $42{ }^{\circ} \mathrm{C}$ as a result of $r n h A$ and $r n h B$ double mutation have been previously described (Itaya et al., 1999). The thermosensitive phenotype can be relieved by delivering plasmids that carry a functional RNase $\mathrm{H}$ gene. This system, which provides a simple and convenient way to probe the functionality of an RNase $\mathrm{H}$ encoding gene, has been successfully used to identify $r n h B$ and $r n h C$ genes of $B$. subtilis. Here, we used the E. coli strain MIC2067 (an rnhA-rnhB double mutant strain, kindly provided by $M$. Itaya) and transformed it with plasmid pTrc99A-lmo1273, carrying the lmo1273 gene under IPTG-inducible promoter control. Complementation of the thermosensitive phenotype was tested at various IPTG levels, by evaluating the capacity of the recombinant $E$. coli to form colonies on plates incubated at $37{ }^{\circ} \mathrm{C}$ or $42{ }^{\circ} \mathrm{C}$. As shown in Fig. 1, while MIC2067 was severely impaired in its ability to form colonies at $37{ }^{\circ} \mathrm{C}$ and $42{ }^{\circ} \mathrm{C}$; normal growth was restored in the complemented strain upon IPTG induction $(25 \mu \mathrm{M}$ IPTG) at these two temperatures (i.e. the number of c.f.u. recorded at these two temperatures was similar to that at $30{ }^{\circ} \mathrm{C}$ ).

\section{Construction and analysis of $\Delta / m 01273$ chromosomal mutants of EGD-e}

All our attempts to inactivate $l m o 1272$ by allelic exchange were unsuccessful (see Methods for details), suggesting that lmo1272 is an essential gene in L. monocytogenes, as the homologous $y l f Q$ gene is in B. subtilis (Uicker et al., 2007). In contrast, inactivation of $l m o 1273$ was tolerated and we successfully generated two chromosomal $\Delta$ lmo1273 deletion mutants of EGD-e: a deletion removing the entire coding sequence (designated $\Delta$ lmo1273) and an internal deletion of 224 bases (designated lmo1273-ID).

We first evaluated the growth of the two lmo1273 mutants in BHI medium, at various temperatures (from $4{ }^{\circ} \mathrm{C}$ to $42{ }^{\circ} \mathrm{C}$ ). The growth rate of the two mutants was identical and only slightly reduced as compared to that of wild-type EGD-e (Supplementary Fig. S2a). We examined the wild- 


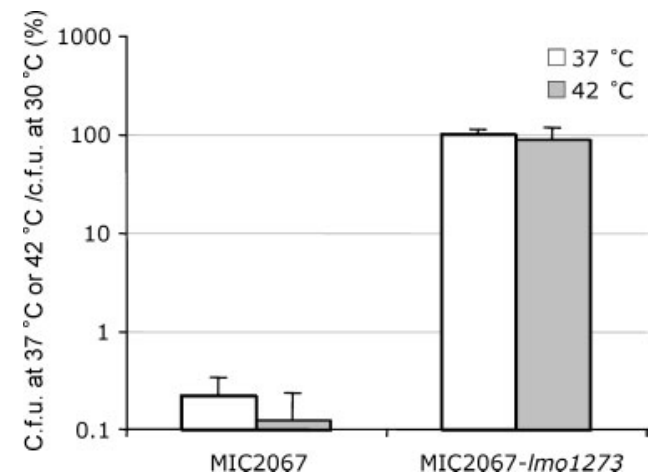

Fig. 1. Functional complementation assay. E. coli MIC2067 is a temperature-sensitive strain resulting from the inactivation of the $r n h A$ and $r n h B$ genes (Itaya et al., 1999). MIC2067 was transformed with a plasmid carrying Imo1273 under the control of an IPTG-inducible promoter (pTrc99A-/mo1273). The capacity of the recombinant strain to form colonies on plates incubated at the non-permissive temperatures of $37{ }^{\circ} \mathrm{C}$ or $42{ }^{\circ} \mathrm{C}$ is shown here using plates with $25 \mu \mathrm{M}$ IPTG and appropriate antibiotics.

type strain and the lmo1273-ID mutant by electron microscopy in stationary phase at $37{ }^{\circ} \mathrm{C}$. In thin sections both wild-type and mutant bacteria showed a typical morphology of dividing bacteria, with formation of septum, a normal cell wall thickness, and a normal bacterial size $(\sim 2 \mu \mathrm{m})$ (Supplementary Fig. S2b). Thus, inactivation of $l m o 1273$ did not create any major defect in cell wall biogenesis or cell division capacity.

Preliminary proteomic analyses (1D-gel analyses; not shown) did not reveal any visible difference in the protein pattern of the lmo1273 mutants as compared to wild-type EGD-e. Moreover, Western blot analyses of culture supernatants, using either anti-LLO or anti-ActA polyclonal antibodies, did not reveal any detectable defect in protein production in the $\Delta l m o 1273$ mutant as compared to EGDe (data not shown).

\section{Effect of the $\Delta / m 01273$ deletion on intracellular multiplication and cell-to-cell spread}

The ability of the mutant strains to penetrate into and replicate within cells was studied in non-professional phagocytic mammalian epithelial cells (Caco-2). There was no significant difference in the number of viable bacteria between the mutant and the wild-type (although the number of mutant bacteria was slightly lower) at any time in the growth curve (Fig. 2a). We also monitored the intracellular multiplication of the $\Delta l m o 1273$ mutant in bone-marrow-derived macrophages (BMM) and in the murine macrophage-like cell line J774. The mutant did not show any growth defect in either cell type (Fig. 2b, c), indicating that the $1 m o 1273$ gene product is not critical for intracellular survival of $L$. monocytogenes.
We finally examined plaque-formation ability, a measure of intracellular growth and cell-to-cell spread of these bacteria. As shown in Fig. 2(d), the lmo1273 mutant did not show any visible defect in plaque formation, in terms of either numbers or size of plaques, compared to the wildtype strain.

\section{Role of Imo1273 in bacterial virulence}

We first studied the role of the lmo1273 gene in bacterial virulence by determining the $\mathrm{LD}_{50}$ of the mutant strains after i.v. inoculation of Swiss mice (Table 1). The $\mathrm{LD}_{50}$ of the $\Delta l m o 1273$ mutant was estimated at $10^{6.5}$. A similar value was recorded with the internal deletion mutant (Imo1273-ID, 10 $\left.0^{6.6}\right)$. These values are 100-fold higher than that of the wild-type strain EGD-e $\left(10^{4.5}\right)$, reflecting a substantial attenuation of virulence, suggesting that lmo1273 might play a role in virulence. When lmo1273 was reintroduced under the control of the $\mathrm{P}_{\text {sipX }}$ promoter in the chromosome of the $\Delta l m o 1273$ mutant (strain $\left.\Delta l m o 1273 / \mathrm{pPL} 2-\mathrm{P}_{\mathrm{X}} l m o 1273\right)$, the virulence of the strain was partially restored $\left(\mathrm{LD}_{50} 10^{5.5}\right)$.

We next monitored the kinetics of bacterial survival in the spleens, livers and brains of mice infected with a dose of $10^{6.1}$ bacteria per mouse. At this dose, the mice infected with EGD-e or the complemented strain $\Delta l m o 1273 /$ pPL2$\mathrm{P}_{\mathrm{X}}$ lmo1273 died within the first 4 days following infection. In contrast, all the mice infected with the mutant strain showed reduced symptom of illness and none of them died. As shown in Fig. 3, the $\Delta l m o 1273$ mutant showed a drastic reduction of multiplication in all the target organs tested. In the spleen, at day 3, a 10-fold reduction in bacterial counts was recorded as compared with EGD-e; and at day $6,95 \%$ of the bacteria were eliminated from the spleen. In the liver, at day 3 a 150 -fold reduction in bacterial counts was recorded; and at day 6 , bacteria had been eliminated from nearly all the mice. Moreover, the brains of mice infected with the $\Delta l m o 1273$ mutant strain were never highly infected, while the count in the brain reached $10^{5}-$ $10^{6}$ c.f.u. with the wild-type or the complemented strain.

Taken together, these data demonstrate that the $\Delta l m o 1273$ mutant is severely impaired in in vivo survival.

\section{Overexpression of Imo1273 in wild-type EGD-e}

Transformation of EGD-e with a multicopy plasmid carrying lmo1273 preceded by the promoter of sipX (EGD-e/pP $P_{\mathrm{X}} l m o 1273$ ) led to the overproduction of Lmo1273. As shown in Table 3, the amount of lmo1273 transcripts produced by this strain is about eightfold higher than that in EGD-e (see below). As observed for the $\Delta$ lmo1273 strain, the overproducing strain had a slight growth defect in $\mathrm{BHI}$ at $37{ }^{\circ} \mathrm{C}$ compared to a control strain carrying the pAT28 plasmid (Fig. 4a). EGD-e/pP $\mathrm{P}_{\mathrm{X}} l m o 1273$ appeared to be attenuated in vivo, as determined by $\mathrm{LD}_{50}$ analysis in the mouse model (Table 1) and by monitoring survival in infected target organs (Fig. $4 \mathrm{~b}$ ). The $\mathrm{LD}_{50}$ value 
(a)

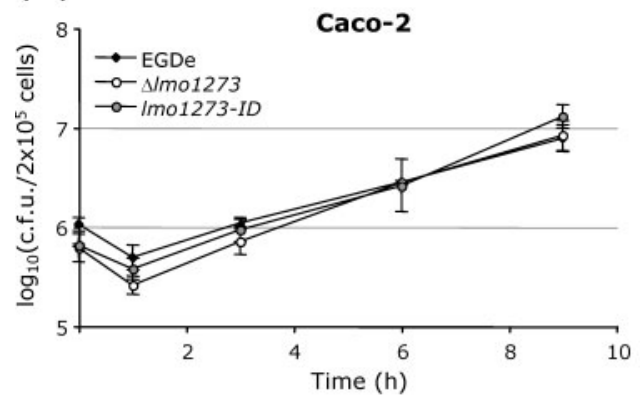

(b)

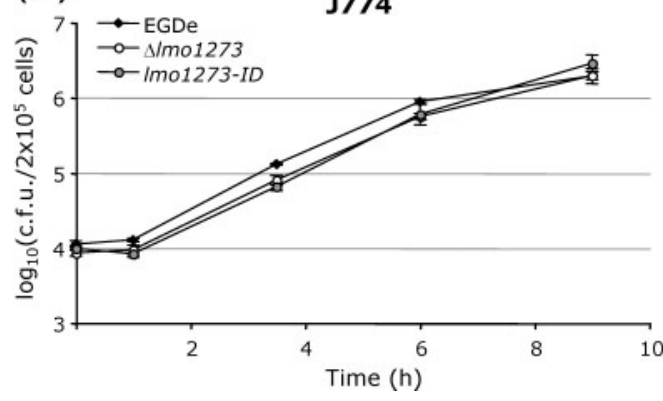

(c)

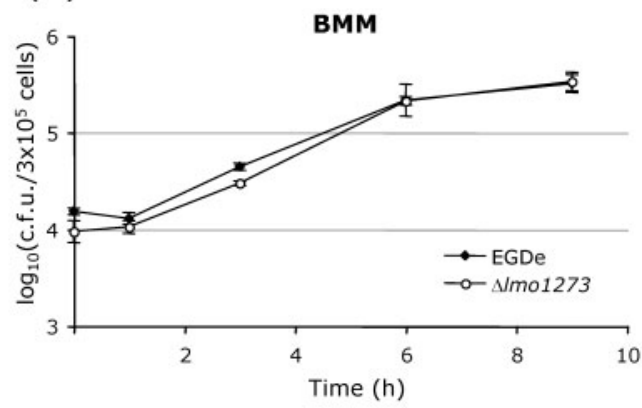

(d)

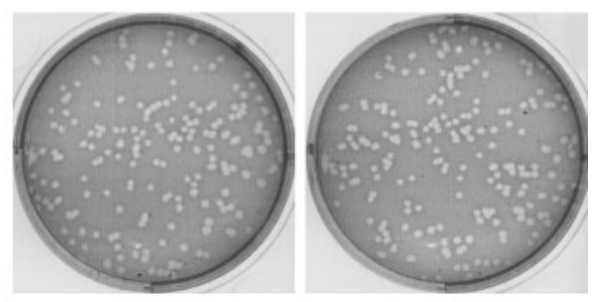

Fig. 2. Intracellular survival. (a, b, c) Kinetics of intracellular multiplication of enterocytic Caco-2 cells (a), J774 macrophage-like cells (b) and bone-marrow-derived macrophages (BMM) from BALB/c mice (c). Invasion and intracellular multiplication was monitored over a $9 \mathrm{~h}$ period in the presence of gentamicin $\left(50 \mu \mathrm{g} \mathrm{ml} \mathrm{l}^{-1}\right.$ final concentration). Data shown represent the means \pm SD of one of at least two independent experiments performed in triplicate with similar results. (d) Cell-to-cell spreading assay. L929 murine fibroblast cells were infected with L. monocytogenes EGD-e (left) or its isogenic $\Delta /$ mo1273 mutant (right) for $2 \mathrm{~h}$ at $37^{\circ} \mathrm{C}$ in a humidified incubator and subsequently incubated for $30 \mathrm{~min}$ in the presence of $10 \mu \mathrm{g}$ gentamicin ml $\mathrm{m}^{-1}$. The plates were then agarose overlaid and were observed for plaques after an additional incubation at $37{ }^{\circ} \mathrm{C} 3$ days post-infection.

of $10^{6.2}$ recorded with $\mathrm{EGD}-\mathrm{e} / \mathrm{pP} \mathrm{X}_{\mathrm{X}} l m o 1273$ should be compared to that of $10^{5.4}$ recorded with EGD-e carrying pAT28 without insert, thus reflecting a 6.3-fold reduction of virulence. A $\sim 100$-fold decrease in the number of bacteria recovered in the spleens, livers and brains of infected animals collected 5 days after infection was observed with EGD-e/pP $\mathrm{X}_{\mathrm{X}}$ lmo1273 as compared to EGDe/pAT28. These results indicated that overproduction of Lmo1273 impaired virulence of $L$. monocytogenes.

Table 1. Lethal dose $50 \%$ (determined in Swiss mice 10 days after i.v. inoculation)

\begin{tabular}{|lc|}
\hline Strain & LD $_{\mathbf{5 0}}$ \\
\hline EGD-e & \\
EGD-e $\Delta l m o 1273$ & $10^{4.5}$ \\
EGD-e $l$ mo1273-ID & $10^{6.5}$ \\
EGD-e $\Delta l m o 1273 /$ pPL2-P ${ }_{\mathrm{X}} l$ mo1273 & $10^{6.6}$ \\
EGD-e/pAT28 & $10^{5.5}$ \\
EGD-e/pP $l m o 1273$ & $10^{5.4}$ \\
EGD-e $\Delta l m o 0847$ & $10^{6.2}$ \\
& $10^{5.2}$ \\
\hline
\end{tabular}

\section{Transcriptomic analyses}

Since $l m o 1273$ is co-transcribed with sipZ (lmo1271) in $L$. monocytogenes (Bonnemain et al., 2004), we first investigated the potential involvement of this putative RNase HII in regulation of sip genes by real-time PCR, using sip primers (see Supplementary Table S1). The levels of sip transcripts were similar in the $\Delta l m o 1273$ mutant and in the wild-type strain during exponential growth in BHI medium (data not shown). We then evaluated the impact of either the deletion or the overexpression of 1 mo1273 on the transcriptome of EGD-e, using microarray technology. Transcriptomic analyses were carried out to compare (i) wild-type EGD-e with its isogenic $\Delta l m o 1273$ mutant; and (ii) wild-type EGD-e with the Lmo1273-overproducing strain (EGD-e/pP $\mathrm{X}_{\mathrm{X}}$ lmo1273). No significant difference was apparent from the comparison of the wild-type versus the $\Delta l m o 1273$ mutant. However, analysis of the expression profile of the overexpressing strain (EGD-e/pP $\mathrm{P}_{\mathrm{X}}$ lmo1273) revealed that 88 genes were differentially transcribed compared to the wild-type strain. Among these genes, 17 were downregulated (see Table 2) and 71 were upregulated (see Table 3). The deletion or the overexpression of lmo1273 had no impact on the expression of any of the other four genes of the sip locus, including 1 mo1272. 
(a)

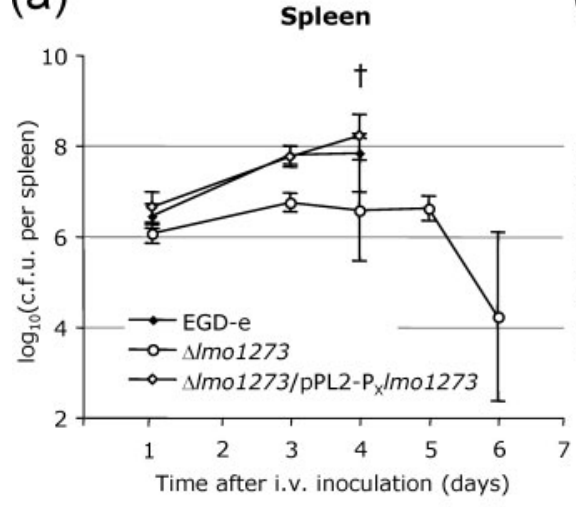

(b)

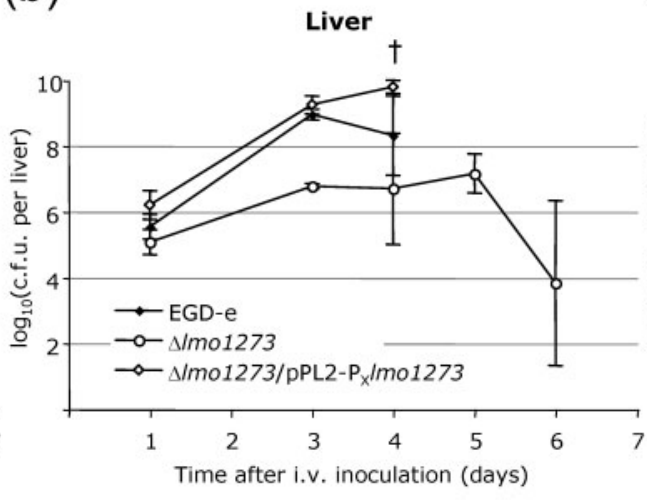

(c)

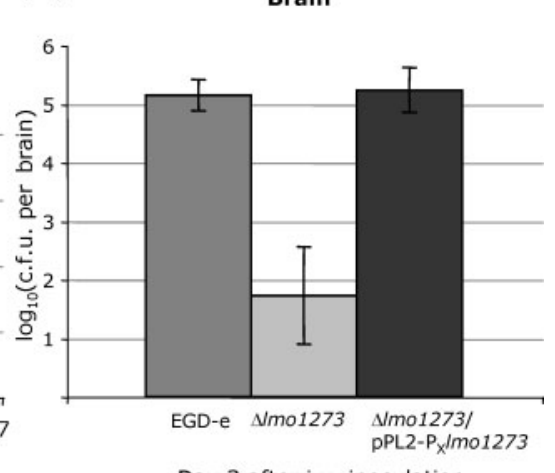

Day 3 after i.v. inoculation

Fig. 3. Kinetics of in vivo multiplication. The growth of EGD-e $(\diamond)$, its isogenic $\Delta /$ mo1273 mutant $(\bigcirc)$ and the complemented strain ( $\Delta /$ mo 1273/pPL2-PXImo1273; $\diamond)$ were monitored over a 6 day period in target organs of mice infected i.v. with a dose of $10^{6.1}$ bacteria per mouse. (a) Spleen; (b) liver; (c) brain at day 3 after i.v. inoculation. Values and error bars represent the means and standard deviation of the number (in $\log _{10}$ ) of bacteria per organ (five mice per point). $\dagger$ indicates that the majority of mice infected with the wild-type or the complemented strain died before day 4. Thus only three mice infected with EGD-e and two mice infected with $\Delta /$ mo1273/pPL2-PXImo1273 could be sacrificed at day 4 .

Among the 17 genes that were downregulated when lmo1273 was overexpressed, 7 genes encode transporters, mainly amino acid or oligopeptide transporters (5/7).
Among the genes upregulated when $l m o 1273$ is overexpressed, we found genes encoding mainly proteins of unknown functions (33/71) and genes associated with

Table 2. Genes downregulated in the context of Imo1273 overexpression

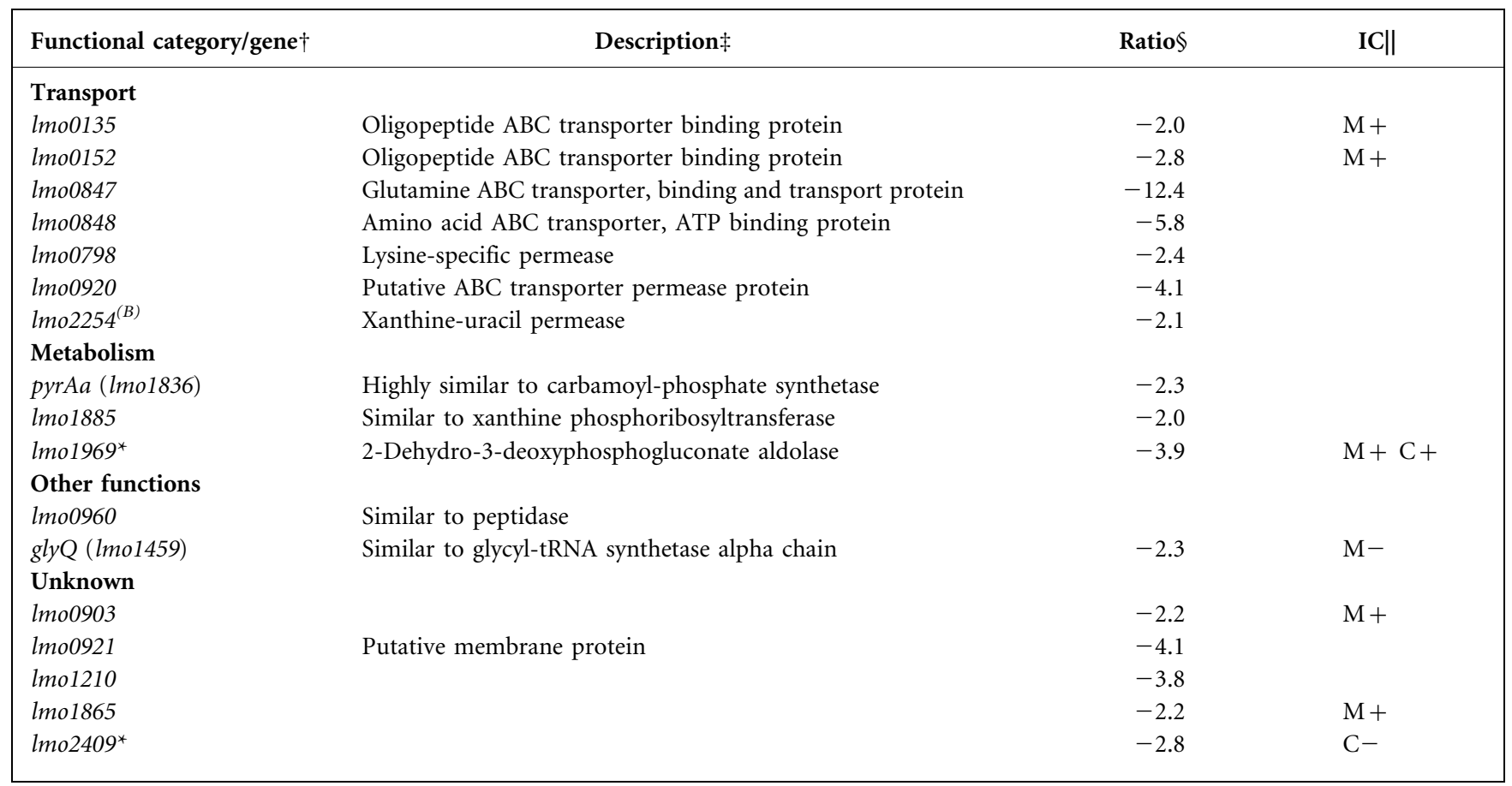

$\dagger$ Genes labelled with an asterisk ${ }^{*}$ ) have no orthologue in the non-pathogenic species L. innocua. Genes labelled with ${ }^{(B)}$ have been previously identified as sigma B-downregulated genes (Hain et al., 2006).

‡Description given by the Listilist web server http://genolist.pasteur.fr/ListiList/index.html.

$\$$ Ratio of wild-type EGD-e to EGD-e/pP $\mathrm{X}_{\mathrm{X}}$ lmo1273. The minus sign indicates that the genes are repressed when $l m o 1273$ is overexpressed.

IIIC: genes which have been previously reported as regulated during intracellular infection of macrophages (M) or Caco-2 cells (C). +, Intracellularly upregulated genes; -, intracellularly downregulated genes. 
(a)

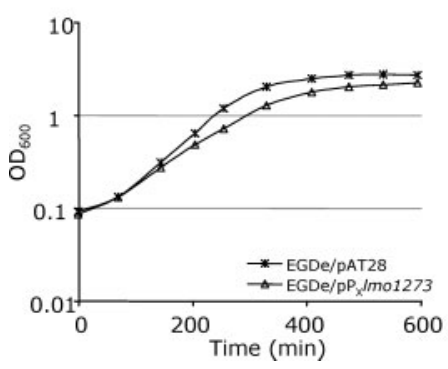

(b)

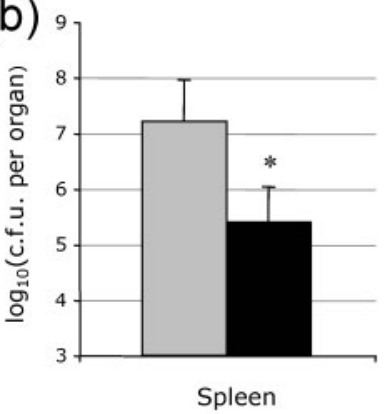

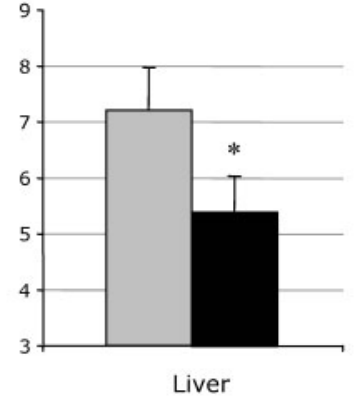

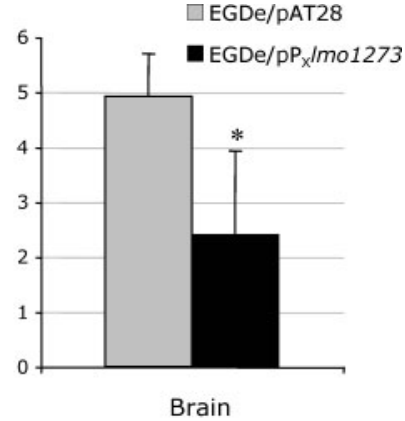

Fig. 4. Overexpression of $I m o 1273$ in wild-type EGD-e. The gene $I m 01273$, expressed under the control of the sip $X$ promoter $\left(P_{X}\right)$ and carried on pAT28 (pP $/$ Imo1273), was introduced into EGD-e by electroporation. EGD-e transformed with pAT28 alone was used as a control. (a) Bacterial growth in BHI broth; (b) bacterial counts in the target organs at day 5 after i.v. inoculation of $10^{5.4}$ bacteria per mouse. Values and error bars represent the means and standard deviation of the number (in $\log _{10}$ ) of bacteria per organ (five mice per point). ${ }^{*}$ indicates a $P$-value $<0.05$ (Student's $t$-test).

metabolism (16/71) or transport functions (7/71). Five genes encode proteins predicted to be associated with peptidoglycan (PG), three of which have previously been experimentally identified as being anchored to the PG by their LPXTG motif by the sortase A (Pucciarelli et al., 2005). This differential expression of surface proteins (transport proteins or PG-associated proteins) prompted us to analyse adhesion to non-phagocytic cells. However, no significant difference in adhesion to Caco-2 cells was observed for the overproducing strain compared to the wild-type (data not shown). Four putative transcription regulators are upregulated, two of which have no orthologue in the non-pathogen L. innocua. Another four genes encode proteins related to stress. Finally, 30 of the 71 genes are preceded by a sigma B promoter as identified by Kazmierczak et al. (2003), suggesting that they might also be regulated in response to stress conditions.

Interestingly, more than $50 \%$ of the genes identified by this transcriptomic analysis (49/88 identified) were also found to be regulated during infection of macrophages (Chatterjee $e t$ al., 2006) or Caco-2 cells (Joseph et al., 2006). It is also worth noting that 10/88 genes have no orthologue in the nonpathogenic species L. innocua (Glaser et al., 2001).

To verify the microarray transcription data, we conducted real-time RT-PCR analysis for $10 \%$ of the differentially regulated genes. The fold induction of 1 mo 1273 determined by the two techniques was the same. Qualitative correlation between the two experiments was observed ( $r=0.86$; see Supplementary Fig. S3) despite some quantitative variations between the results of the hybridization and the realtime RT-PCR, as previously reported (Joseph et al., 2006; Stintzi, 2003).

\section{Inactivation of Imo0847 impairs virulence}

Among the 17 downregulated genes identified by the transcriptomic analysis of the lmo1273-overexpressing strain, two genes $1 m o 0847$ and $l m o 0848$, possibly belonging to the same operon, were the most severely downregulated $(-12.4$ and -5.8 , respectively; Table 2$)$. These two genes, which could be direct targets of Lmo1273, encode a putative glutamine transporter of the $\mathrm{ABC}$ family (Glaser et al., 2001). Of interest, ArpJ, a paralogue of Lmo0847, has been previously shown to be important intracellularly (Klarsfeld et al., 1994). In order to determine if the downregulation of this transporter could account for, at least in part, the phenotype of the lmo1273 mutants, we constructed a deletion mutant of the gene $\operatorname{lmo} 0847$ (see Methods). The $\mathrm{LD}_{50}$ of this mutant was $10^{5.2}$ in Swiss mice by the i.v. route. The level of attenuation of this mutant (about fivefold, as compared to wild-type EGD-e) is of the same order as that of the lmo1273-overexpressing strain EGD-e/pP $\mathrm{X}_{\mathrm{X}} l m o 1273$ (about fivefold as compared to the control strain EGD-e/pAT28). Thus, the downregulation of $1 m 00847-0848$ expression could account by itself for the decrease of virulence in the lmo1273-overexpressing strain.

\section{DISCUSSION}

We addressed here the role of the $1 m o 1273$ gene in $L$. monocytogenes virulence. For this, we constructed two chromosomal deletion mutants as well as an overexpressing strain. We monitored the intracellular survival properties of the recombinant L. monocytogenes strains, in cell culture assays and in vivo. We also performed a whole-genome transcriptomic analysis of a strain overproducing Lmo1273 to identify Lmo1273-regulated genes.

\section{Imo1273, a novel gene involved in $L$. monocytogenes virulence}

Inactivation of $1 m o 1273$ had no detectable impact on intracellular survival of $L$. monocytogenes in any of the cell culture assays that we performed. However, it provoked a 
Table 3. Genes upregulated in the context of $I$ mo1273 overexpression

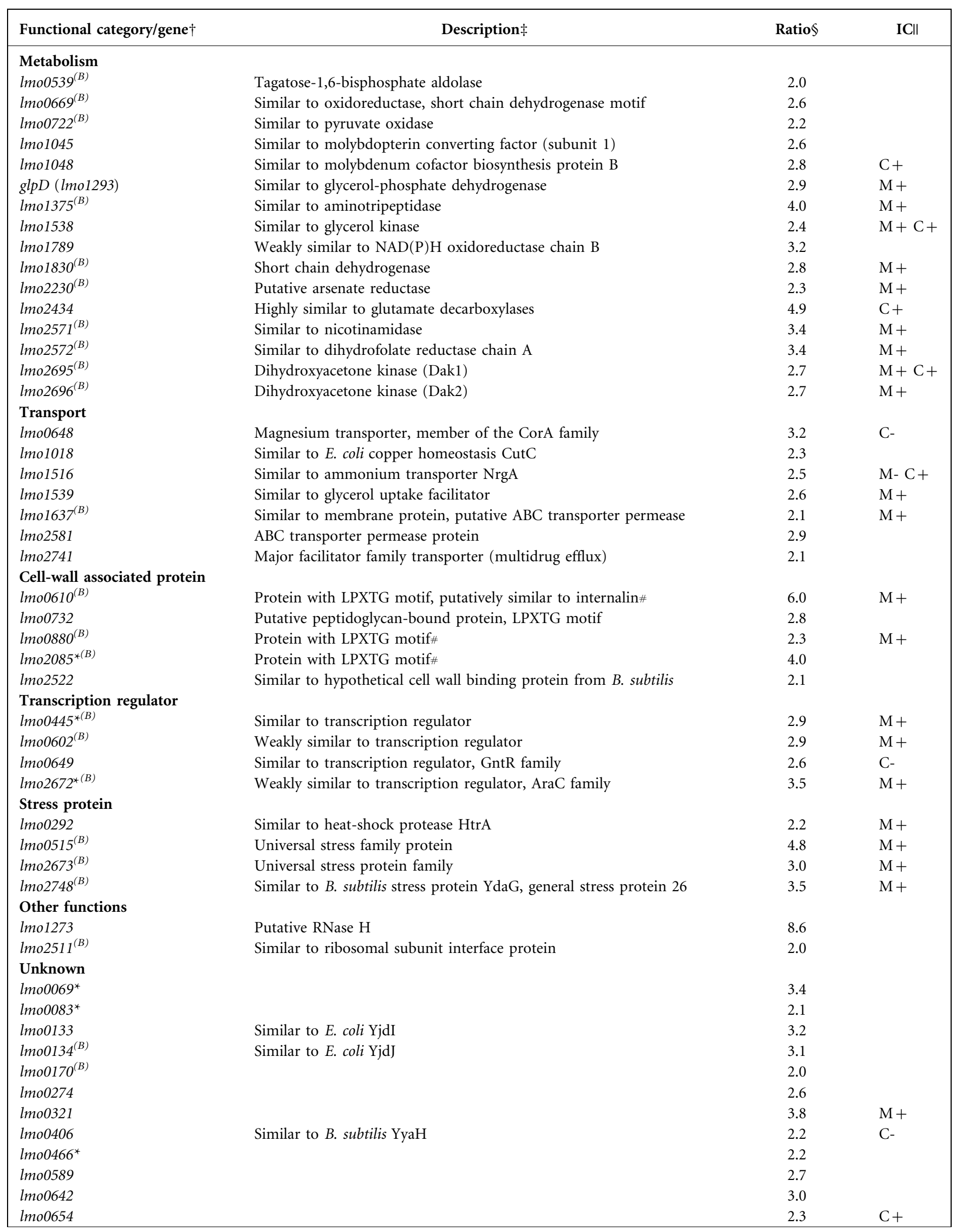


Table 3. cont.

\begin{tabular}{|c|c|c|c|}
\hline Functional category/gene $\dagger$ & Description $\ddagger$ & Ratio $\$$ & $\mathrm{IC} \|$ \\
\hline $\operatorname{lmo} 0670^{(B)}$ & & 3.0 & \\
\hline $\operatorname{lmo0794}$ & Similar to B. subtilis YwnB & 2.5 & $\mathrm{M}+\mathrm{C}+$ \\
\hline $\operatorname{lmo0911^{(B)}}$ & & 2.2 & $M+$ \\
\hline $\operatorname{lmo0937}$ & & 2.1 & \\
\hline $\operatorname{lmo0953^{(B)}}$ & & 2.7 & $M+$ \\
\hline $\operatorname{lmo0994^{(B)}}$ & & 2.8 & $\mathrm{M}+$ \\
\hline $\operatorname{lmo1124}$ & & 3.3 & \\
\hline $\operatorname{lmo} 1140^{(B)}$ & & 4.0 & $\mathrm{M}+\mathrm{C}+$ \\
\hline $\operatorname{lmo} 1241^{(B)}$ & & 4.9 & $M+$ \\
\hline $\operatorname{lmo} 1518$ & & 2.4 & $\mathrm{M}+$ \\
\hline $\operatorname{lmo} 1526^{(B)}$ & & 2.9 & $M+$ \\
\hline $\operatorname{lmo} 1694^{(B)}$ & & 2.3 & $M+$ \\
\hline $\operatorname{lmo} 1704$ & & 2.1 & \\
\hline $\operatorname{sep} A(\operatorname{lmo} 2157)^{\star(B)}$ & & 2.4 & $\mathrm{C}+$ \\
\hline $\operatorname{lmo} 2158^{(B)}$ & Similar to B. subtilis YwmG & 2.6 & $M+$ \\
\hline $\operatorname{lmo} 2387^{*(B)}$ & & 3.1 & \\
\hline $\operatorname{lmo} 2391^{(B)}$ & Similar to B. subtilis YhfK & 2.7 & $M+$ \\
\hline $\operatorname{lmo} 2570^{(B)}$ & Putative membrane protein & 3.3 & $M+$ \\
\hline $\operatorname{lmo} 2603^{(B)}$ & & 2.4 & \\
\hline $\operatorname{lmo} 2697^{(B)}$ & & 2.6 & $\mathrm{M}+$ \\
\hline $\operatorname{lmo} 2740$ & & 2.1 & \\
\hline
\end{tabular}

$\dagger$ Genes labelled with an asterisk $\left(^{*}\right)$ have no orthologue in the non-pathogenic species L. innocua. Genes labelled ${ }^{(B)}$ have been previously identified as sigma B-upregulated genes (Hain et al., 2006).

$\ddagger$ Description given by the Listilist web server http://genolist.pasteur.fr/ListiList/index.html. Proteins labelled \# have been experimentally identified as anchored to the peptidoglycan by the sortase SrtA (Pucciarelli et al., 2005).

§Ratio of EGD-e/pP $\mathrm{X}$ lmo1273 to wild-type EGD-e.

IIIC: genes which have been previously reported as regulated during intracellular infection of macrophages (M) or Caco-2 cells (C). +, Intracellularly upregulated genes; -, intracellularly downregulated genes.

severe attenuation of virulence in the mouse model. Moreover, overexpresion of $l m o 1273$ (in a wild-type EGD-e genetic background) also led to an attenuation of virulence, implying that not only Lmo1273 expression is required to promote an efficient infection but also an appropriate level of expression. Most of the L. monocytogenes attenuated mutants described so far exhibited various growth defects in cell culture models (impaired adhesion, phagosomal escape, intracytosolic multiplication, movement or cell-to-cell spread...) associated - or not - with in vivo attenuation. The non-canonical virulence phenotype of the lmo1273 mutants has however also been reported (Engelbrecht et al., 1998; Sabet et al., 2008). Of particular interest, the absence of in vitro defects in an in vivo-attenuated inlJ mutant of L. monocytogenes was recently explained by showing that InlJ (a surface protein of the internalin family) was not produced by bacteria grown in vitro (including in infected cells) but was specifically expressed at the bacterial surface in vivo (Sabet et al., 2008). In the case of $l m o 1273$, the situation is probably more complex, since overexpression of 1 mo1273 modulates the expression of many other genes. Inactivation of lmo1273 may alter the bacterial fitness in infected organs and/or influence bacterial recognition by the host immune system.

Previous studies have shown that the three bacterial RNases $\mathrm{H}$ are required for the removal of RNA moieties of RNADNA hybrids such as primers from Okazaki fragments during lagging-strand DNA synthesis, and may thus be directly involved in DNA replication (Crouch, 1990; Qiu et al., 1999). However, only RNase HII is capable of removing single RNA from DNA-RNA/DNA-DNA hybrids, such as those produced when RNA is misincorporated into DNA (Haruki et al., 2002; Rydberg \& Game, 2002). A recent extensive phylogenetic analysis of 353 prokaryotic genomes revealed that the RNase $\mathrm{H}$ group has evolved in such a way that genes encoding RNase HI and RNase HIII are inherited in a mutually exclusive manner, which may be attributed to the functional redundancy of the two enzymes. Of note, it has been shown, in yeast, that RNase HII is involved in both DNA replication and DNA repair (Arudchandran et al., 2000; Rydberg \& Game, 2002). Moreover, in Haemophilus influenzae, rnhA mutants lacking RNase HI activity show an approximately threefold increase in the mutation rates of tetranucleotide repeats 
(Bayliss et al., 2005), thus affecting phase variation, a key process in the pathogenicity of this organism.

Thus, in L. monocytogenes $r n h B$ might also be involved in DNA replication and/or DNA repair, which remains to be experimentally determined.

\section{Lmo1273, a novel pleiotropic regulator of $L$. monocytogenes?}

In order to get further insight into the mechanisms by which Lmo1273 could influence bacterial virulence, we performed whole-genome microarray analyses. These analyses revealed significant differences between EGD-e and an Lmo1273-overproducing strain (EGD-e/plmo1273). In contrast, no major difference could be detected between EGD-e and and the $\Delta l m o 1273$ mutant, suggesting that, under the conditions used in our assays, the level of expression of lmo1273 in EGD-e is probably low.

Seventeen downregulated genes were recorded when lmo1273 was overexpressed. Notably, approximately onethird (5/17) of the genes encode amino acid or oligopeptide transporters. A significantly larger number of genes appeared to be upregulated when lmo1273 was overexpressed. These genes encompassed a variety of predicted functions, and included genes associated with metabolism (16/71) or transport functions (7/71). Of interest, among the four genes encoding proteins bearing an LPxTG motif and predicted to be associated with peptidoglycan (PG), three of them have been experimentally shown to be PG-anchored.

Strikingly, 39 genes out of the 71 upregulated are sigma Bdependent genes (Hain et al., 2008), supporting the notion of a link between $1 m o 1273$-dependent regulation and stress response in L. monocytogenes (Hain et al., 2008). Thirty of these 39 genes are preceded by a sigma $\mathrm{B}$ consensus box and could be directly regulated by sigma B. Of note, Imo1272 is also preceded by a putative sigma B promoter sequence. However, the transcriptomic analysis of the sigma B regulon of L. monocytogenes (Hain et al., 2008) reveals that none of the genes of the sip locus is under the control of sigma $\mathrm{B}$.

Interestingly, almost half of the genes (7/17) that were repressed upon overproduction of 1 mo1273 belonged to amino acid and/or oligopeptide transport systems. This observation prompted us to evaluate the virulence of a mutant in one of these transporters. We chose $1 m o 0847$, the most severely downregulated gene (see Table 2 ). We found that inactivation of $1 m o 0847$, encoding a putative glutamine binding protein of a dedicated $\mathrm{ABC}$ transporter, led to a modest but significant reduction of virulence. It is thus reasonable to assume that the strong attenuation of virulence of the lmo1273 mutant is due to a sum of effects, and in particular on genes involved in nutritional adaptation in its animal host.

Future work will be required to determine the precise molecular mechanisms by which the 1 mo1273 gene product functions and controls gene expression. We obtained preliminary indications that 1 mo1273 might encode a genuine RNase $\mathrm{H}$. At this stage, it cannot be excluded that RNase $\mathrm{H}$ activity might also provide a means for $L$. monocytogenes to regulate expression of a series of genes whose expression is under the control of antisense RNAs. The fact that $l m o 1272$ and $l m o 1273$ are expressed from the same transcript may also reflect a link between RNase H activities and ribosomal biogenesis.

Finally, the fact that inactivation of $\operatorname{rnh} B$ led to the production of viable bacteria strongly suggests that, as observed in other bacterial species possessing more than one RNase $\mathrm{H}$, the lack of RNase HII can compensated at least in part by the other RNase $\mathrm{H}$ encoded by the $L$. monocytogenes genome.

\section{ACKNOWLEDGEMENTS}

This work was supported by CNRS, INSERM and Université Paris V. Work carried out in Giessen was supported by EuroPathoGenomics Network, and the DFG through SFB535 Project B14 (T. H. and T. C.).

\section{REFERENCES}

Arnaud, M, Chastanet, A \& Débarbouillé, M. (2004). New vector for efficient allelic replacement in naturally nontransformable, low-GCcontent, gram-positive bacteria. Appl Environ Microbiol 70, 68876891.

Arudchandran, A., Cerritelli, S., Narimatsu, S., Itaya, M., Shin, D. Y., Shimada, Y. \& Crouch, R. J. (2000). The absence of ribonuclease H1 or $\mathrm{H} 2$ alters the sensitivity of Saccharomyces cerevisiae to hydroxyurea, caffeine and ethyl methanesulphonate: implications for roles of RNases H in DNA replication and repair. Genes Cells 5, 789-802.

Bayliss, C. D., Sweetman, W. A. \& Moxon, E. R. (2005). Destabilization of tetranucleotide repeats in Haemophilus influenzae mutants lacking RnaseHI or the Klenow domain of PolI. Nucleic Acids Res 33, 400-408.

Bigot, A., Botton, E., Dubail, I. \& Charbit, A. (2006). A homolog of Bacillus subtilis trigger factor in Listeria monocytogenes is involved in stress tolerance and bacterial virulence. Appl Environ Microbiol 72, 6623-6631.

Bonnemain, C., Raynaud, C., Reglier-Poupet, H., Dubail, I., Frehel, C., Lety, M. A., Berche, P. \& Charbit, A. (2004). Differential roles of multiple signal peptidases in the virulence of Listeria monocytogenes. Mol Microbiol 51, 1251-1266.

Chatterjee, S. S., Hossain, H., Otten, S., Kuenne, C., Kuchmina, K., Machata, S., Domann, E., Chakraborty, T. \& Hain, T. (2006). Intracellular gene expression profile of Listeria monocytogenes. Infect Immun 74, 1323-1338.

Condon, C. (2003). RNA processing and degradation in Bacillus subtilis. Microbiol Mol Biol Rev 67, 157-174.

Crouch, R. J. (1990). Ribonuclease H: from discovery to 3D structure. New Biol 2, 771-777.

de Chastellier, C. \& Berche, P. (1994). Fate of Listeria monocytogenes in murine macrophages: evidence for simultaneous killing and survival of intracellular bacteria. Infect Immun 62, 543-553.

Dramsi, S., Biswas, I., Maguin, E., Braun, L., Mastroeni, P. \& Cossart, P. (1995). Entry of Listeria monocytogenes into hepatocytes requires 
expression of InIB, a surface protein of the internalin multigene family. Mol Microbiol 16, 251-261.

Engelbrecht, F., Dominguez-Bernal, G., Hess, J., Dickneite, C., Greiffenberg, L., Lampidis, R., Raffelsbauer, D., Daniels, J. J., Kreft, J. \& other authors (1998). A novel PrfA-regulated chromosomal locus, which is specific for Listeria ivanovii, encodes two small, secreted internalins and contributes to virulence in mice. Mol Microbiol 30, 405-417.

Farber, J. M. \& Peterkin, P. I. (1991). Listeria monocytogenes, a foodborne pathogen. Microbiol Rev 55, 476-511.

Finney, D. J. (1971). Statistical aspects of monitoring for dangers in drug therapy. Methods Inf Med 10, 237-245.

Frehel, C. \& Leduc, M. (1987). Cytochemical localization of lipopolysaccharides during peptidoglycan degradation of Escherichia coli cells. J Bacteriol 169, 210-217.

Fukushima, S., Itaya, M., Kato, H., Ogasawara, N. \& Yoshikawa, H. (2007). Reassessment of the in vivo functions of DNA polymerase I and RNase H in bacterial cell growth. J Bacteriol 189, 8575-8583.

Glaser, P., Frangeul, L., Buchrieser, C., Rusniok, C., Amend, A., Baquero, F., Berche, P., Bloecker, H., Brandt, P. \& other authors (2001). Comparative genomics of Listeria species. Science 294, 849852.

Hain, T., Steinweg, C., Kuenne, C. T., Billion, A., Ghai, R., Chatterjee, S. S., Domann, E., Kärst, U., Goesmann, A. \& other authors (2006). Whole-genome sequence of Listeria welshimeri reveals common steps in genome reduction with Listeria innocua as compared to Listeria monocytogenes. J Bacteriol 188, 7405-7415.

Hain, T., Hossain, H., Chatterjee, S. S., Machata, S., Volk, U., Wagner, S., Brors, B., Haas, S., Kuenne, C. T. \& other authors (2008). Temporal transcriptomic analysis of the Listeria monocytogenes EGD-e sigmaB regulon. BMC Microbiol 8, 20.

Hamon, M., Bierne, H. \& Cossat, P. (2006). Listeria monocytogenes: a multifaceted model. Nat Rev Microbiol 4, 423-434.

Haruki, M., Tsunaka, Y., Morikawa, M. \& Kanaya, S. (2002). Cleavage of a DNA-RNA-DNA/DNA chimeric substrate containing a single ribonucleotide at the DNA-RNA junction with prokaryotic RNases HII. FEBS Lett 531, 204-208.

Itaya, M., Omori, A., Kanaya, R., Crouch, J., Tanaka, T. \& Kondo, K. (1999). Isolation of RNase $\mathrm{H}$ genes that are essential for growth of Bacillus subtilis 168. J Bacteriol 181, 2118-2123.

Joseph, B., Przybilla, K., Stuhler, C., Schauer, K., Slaghuis, J., Fuchs, T. M. \& Goebel, W. (2006). Identification of Listeria monocytogenes genes contributing to intracellular replication by expression profiling and mutant screening. J Bacteriol 188, 556-568.

Katayanagi, K., Miyagawa, M., Matsushima, M., Ishikawa, M., Kanaya, S., Ikehara, M., Matsuzaki, T. \& Morikawa, K. (1990). Three-dimensional structure of ribonuclease H from E. coli. Nature 347, 306-309.

Kazmierczak, M. J., Mithoe, S. C., Boor, K. J. \& Wiedman, M. (2003). Listeria monocytogenes sigma $B$ regulates stress response and virulence functions. J Bacteriol 185, 5722-5734.

Klarsfeld, A. D., Goossens, P. L. \& Cossart, P. (1994). Five Listeria monocytogenes genes preferentially expressed in infected mammalian cells: plcA, purH, purD, pyrE and an arginine ABC transporter gene, arpJ. Mol Microbiol 13, 585-597.

Lauer, P., Chow, M. J., Loessner, M. J., Portnoy, D. A. \& Calendar, R. (2002). Construction, characterization and use of two Listeria monocytogenes site-specific phage integration vectors. J Bacteriol 184, 4177-4186.
Lingnau, A., Domann, E., Hudel, M., Bock, M., Nichterlein, T., Wehland, J. \& Chakraborty, T. (1995). Expression of the Listeria monocytogenes EGD inlA and inlB genes, whose products mediate bacterial entry into tissue culture cell lines, by PrfA-dependent and -independent mechanisms. Infect Immun 63, 3896-3903.

Matsuo, Y., Morimoto, T., Kuwano, M., Loh, P. C., Oshima, T. \& Ogasawara, N. (2006). The GTP-binding protein YlqF participates in the late step of $50 \mathrm{~S}$ ribosomal subunit assembly in Bacillus subtilis. $J$ Biol Chem 281, 8110-8117.

Morimoto, T., Loh, P. C., Hirai, T., Asai, K., Kobayashi, K., Moriya, S. \& Ogasawara, N. (2002). Six GTP-binding proteins of the Era/Obg family are essential for cell growth in Bacillus subtilis. Microbiology 148, 3539-3552.

Ohtani, N., Haruki, M., Morikawa, M., Crouch, J., Itaya, M. \& Kanaya, R. (1999a). Identification of the genes encoding $\mathrm{Mn}^{2+}$ dependent RNase HII and $\mathrm{Mg}^{2+}$-dependent RNase HIII from Bacillus subtilis: classification of RNase $\mathrm{H}$ into three families. Biochemistry 38, 605-618.

Ohtani, N., Haruki, M., Morikawa, M. \& Kanaya, S. (1999b). Molecular diversities of RNases H. J Biosci Bioeng 88, 12-19.

Park, S. F. \& Stewart, G. S. (1990). High efficiency transformation of Listeria monocytogenes by electroporation of penicillin-treated cells. Gene 94, 129-132.

Pucciarelli, M. G., Calvo, E., Sabet, C., Bierne, H., Cossart, P. \& Garcia-del Portillo, F. (2005). Identification of substrates of the Listeria monocytogenes sortases A and B by a non-gel proteomic analysis. Proteomics 5, 4808-4817.

Qiu, J., Qian, Y., Frank, P., Wintersberger, U. \& Shen, B. (1999). Saccharomyces cerevisiae RNase $\mathrm{H}(35)$ functions in RNA primer removal during lagging-strand DNA synthesis, most efficiently in cooperation with Rad27 nuclease. Mol Cell Biol 19, 8361-8371.

Raynaud, C. \& Charbit, A. (2005). Regulation of expression of type I signal peptidases in Listeria monocytogenes. Microbiology 151, 37693776.

Rydberg, B. \& Game, J. (2002). Excision of misincorporated ribonucleotides in DNA by RNase $\mathrm{H}$ (type 2) and FEN-1 in cellfree extracts. Proc Natl Acad Sci U S A 99, 16654-16659.

Sabet, C., Toledo-Arana, A., Personnic, N., Lecuit, M., Dubrac, S., Poupel, O., Gouin, E., Nahori, M. A., Cossart, P. \& Bierne, H. (2008). The Listeria monocytogenes virulence factor InlJ is specifically expressed in vivo and behaves as an adhesin. Infect Immun 76, 1368-1378.

Stintzi, A. (2003). Gene expression profile of Campylobacter jejuni in response to growth temperature variations. J Bacteriol 185, 20092016.

Uicker, W. C., Schaefer, L., Koenigsknecht, M. \& Britton, R. A. (2007). The essential GTPase $\mathrm{YqeH}$ is required for proper ribosome assembly in Bacillus subtilis. J Bacteriol 189, 2926-2929.

Vazquez-Boland, J. A., Kuhn, M., Berche, P., Chakraborty, T., Dominguez-Bernal, G., Goebel, W. \& Gonzalez-Zorn, B. (2001). Listeria pathogenesis and molecular virulence determinants. Clin Microbiol Rev 14, 584-640.

Vieira, J. \& Messing, J. (1985). Improved M13 phage cloning vectors and host strains: nucleotide sequences of the M13mp18 and pUC19 vectors. Gene 33, 103-119.

Zhang, Y. B., Ayalew, S. \& Lacks, S. A. (1997). The $r n h B$ gene encoding RNase HII of Streptococcus pneumoniae and evidence of conserved motifs in eucaryotic genes. J Bacteriol 179, 3828-3836.

Edited by: H. Ingmer 